\title{
Analysis of 1246 Cases of Orbital Lesions: A Study of 17 Years
}

\author{
Asad Aslam Khan*, Suhail Sarwar, M. Ali Ayaz Sadiq, Munib Ur Rehman, Asad Ullah, \\ Imran Ahmad \\ Institute of Ophthalmology, King Edward Medical University, Mayo Hospital, Lahore, Pakistan \\ Email: ${ }^{*}$ drasad@lhr.comsats.net.pk
}

Received 30 April 2015; accepted 14 June 2015; published 17 June 2015

Copyright (C) 2015 by authors and Scientific Research Publishing Inc.

This work is licensed under the Creative Commons Attribution International License (CC BY). http://creativecommons.org/licenses/by/4.0/

(c) (i) Open Access

\begin{abstract}
Purpose: The aim of this study is to present an analysis of orbital lesions by classifying them according to the site of origin in patients of all ages presenting at a tertiary care eye hospital from 1996 till 2012. Methods: 1637 patients were initially enrolled in this descriptive case series. Clinical data of 1246 patients who completed the study during 17 years were analyzed. Orbital lesions of the patients were examined and managed medically or surgically as per requirement. The histopathological reports of these patients were used to classify the lesions. Results: Out of all cases $54.57 \%(n=680)$ were neoplastic and $45.42 \%(n=566)$ were nonneoplastic lesions. Amongst the neoplastic lesions $86.17 \%(n=586)$ were malignant and $13.82 \%(n=94)$ were benign. Primary orbital lesions were the most common orbital lesions being $963(77.29 \%)$ followed by secondary orbital lesions being $232(18.62 \%)$, hematopoietic reticuloendothelial being $47(3.77 \%)$ and metastatic lesions being $04(0.32 \%)$. Conclusion: Orbital lesions are more common in adults as compared to children. Neoplastic lesions are more common than nonneoplastic lesions, and amongst the neoplastic lesions malignant lesions are more common than benign ones. Primary orbital lesions are the most common orbital lesions followed by secondary orbital lesions, lesions of the hematopoietic reticuloendothelial system and metastatic lesions.
\end{abstract}

\section{Keywords}

Neoplastic Lesions, Primary Orbital Lesions, Secondary Orbital Lesions, Hematopoietic Orbital Lesions, Metastatic Orbital Lesions, Case Study

\section{Introduction}

The orbit, a four-sided pyramidal bony space in the skull, measures approximately $45 \mathrm{ml}$ in an adult human. It "Corresponding author. 
houses the eyeball along with the ocular adnexa and comprises structures derived from all three germinal layers (ectodermal, mesodermal \& endodermal) as well as all the tissues (skin, muscle, connective tissue etc.) in the human body. Therefore it is not surprising that a pathology arising from any of these structures can contribute to the etiology of orbital lesions. But occasionally the orbit is affected by systemic diseases or secondarily by a disorder arising somewhere else in the body. The orbit is surrounded by, and is connected through various foramina and fissures to cranial cavity, nasal cavity and paranasal sinuses; hence diseases arising from the neighborhood can easily infiltrate the orbit and vice versa. The orbit is extensively connected to neuro-vascular system of face, head, neck and brain (particularly dural venous sinuses) and the pathologies of the orbit especially tumors spread quickly via hematogenous route in addition to local spread. True lymphatics have not been found in the orbit but involvement of regional lymph nodes by inflammatory or neoplastic lesion (probably along venous channels) has also been well documented [1].

Orbital lesions can be classified in many ways depending upon tissue of origin (histological, histopathological or embryonal), anatomical site (eyeball, lacrimal gland, eyelids etc.), and clinical course (acute, chronic etc.). One of the commonest and useful classifications is Primary, Secondary \& Metastatic according to the site of origin [2]. The orbital contents include eyeball, optic nerve, main trunks/branches of arteries, veins, and cranial nerves III to VI, lacrimal gland, extraocular muscles, smooth muscles, orbital fat, ligaments, orbital fascia (including periorbita - the periosteal lining of orbit) and skin with its appendages [3]. Orbital lesions can occur in any age group or in either gender, but it has been observed that those arising at a younger age especially malignancies tend to behave more aggressively and an earlier diagnosis and prompt appropriate treatment can result in better prognosis [4].

\section{Materials and Methods}

This descriptive case series was undertaken to analyze different orbital lesions presented during a period of 17 years. The subjects included those who visited Eye Department of Mayo Hospital Lahore, Pakistan during 17 years from 1996 till 2012. This study was undertaken in accordance with Declaration of Helsinki (1964 including its amendments) after approval from Ethical Committee of King Edward Medical University. Out of 1637 cases, 1246 cases of orbital lesions, who gave informed consent and completed the study with complete clinical records, were included in the analysis; the remaining 391 comprised those who left against the medical advice, were lost to follow up or never reported back after being referred/shifted to other departments like Otolaryngology, Neurosurgery or Oncology departments. After detailed history, examination and routine investigations, necessary investigations like Orbital/Ocular Ultrasonography (B Scan), X Ray Orbit/Paranasal sinuses/Cranium, CT scan and Magnetic Resonance Imaging (MRI) were performed. Surgery (usually orbitotomy) was performed when a definite space occupying lesion was identified during investigations. In some cases only biopsy was done to establish a histopathological diagnosis.

\section{Results}

Out of 1246 patients, 57.46\% $(n=716)$ were adults and 42.53\% $(n=530)$ children. Out of all cases $54.57 \%(n=$ $680)$ were neoplastic and $45.42 \%(n=566)$ nonneoplastic lesions. Amongst the neoplastic lesions $86.17 \%(n=$ 586) were malignant and $13.82 \%(n=94)$ were benign. These lesions were divided into following four groups based on their site of origin:

- Primary Orbital Lesions, which originated from the tissues of the orbit. Eye ball being a part of the orbit; therefore its lesions are included in the primary category.

- Secondary Orbital Lesions, which originated from the adjacent structure like Eyelids, Paranasal sinuses, cranial cavity or nasopharynx and invaded the orbit secondarily.

- Haematopoeitic Reticuloendothelial system lesions.

- Metastatic, with primary in the distant organs.

Primary orbital lesions were the most common orbital lesions being 963 (77.29\%) (Figure 1; Table 1) followed by secondary orbital lesions 232 (18.62\%) (Figure 1; Table 2), hematopoietic reticuloendothelial 47 (3.77\%) (Figure 1; Table 3) and metastatic 04 (0.32\%) lesions (Figure 1; Table 4).

\subsection{Primary Orbital Lesions}

Amongst the primary orbital lesions, ocular lesions (Figure 2 and Figure 3) were most common 264 (27.41\%) 


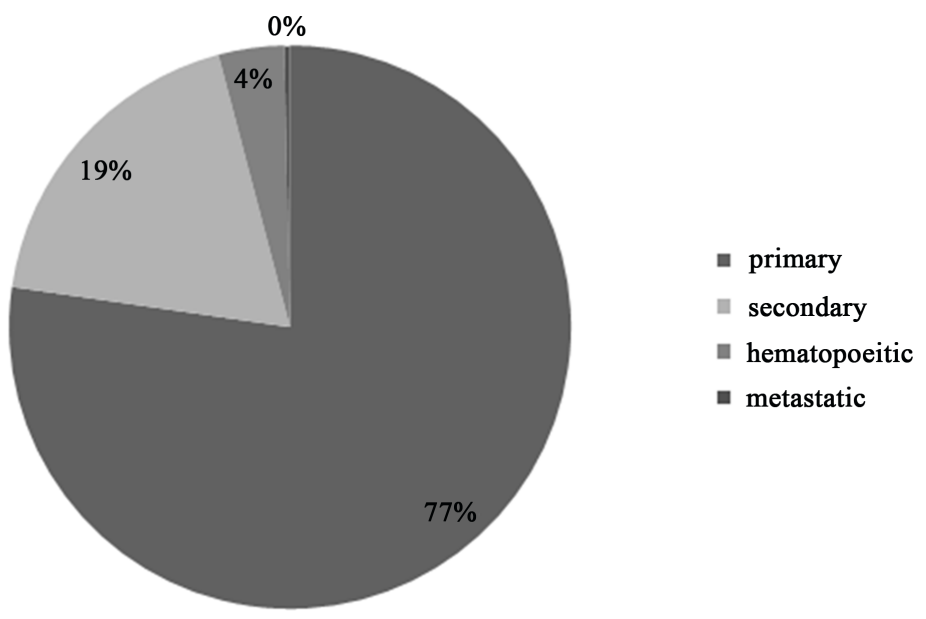

Figure 1. Percentage distribution of patients according to the type of orbital lesions.



Figure 2. Case of retinoblastoma with proptosis.

Table 1. Frequency and breakup of primary orbital lesions.

\begin{tabular}{|c|c|c|c|}
\hline \multicolumn{4}{|c|}{ PRIMARY ORBITAL LESIONS } \\
\hline LESIONS & Frequency (n) & $\begin{array}{l}\text { Proportion of primary } \\
\text { Orbital lesions (\%) }\end{array}$ & $\begin{array}{c}\text { Proportion of } \\
\text { total lesions (\%) }\end{array}$ \\
\hline Ocular & 264 & 27.41 & 21.18 \\
\hline Retinoblastoma & 251 & 26.06 & 20.14 \\
\hline Malignant melanoma & 12 & 01.25 & 00.96 \\
\hline Dysthyroid eye disease & 01 & 00.1 & 00.08 \\
\hline Inflammatory & 173 & 17.96 & 13.88 \\
\hline \multicolumn{4}{|l|}{ Acute } \\
\hline Orbital cellulitis & 29 & 3.01 & 02.32 \\
\hline Subperiosteal abscess & 13 & 1.35 & 01.04 \\
\hline Orbital abscess & 07 & 0.73 & 00.56 \\
\hline Epidural abscess & 01 & 00.1 & 00.08 \\
\hline Posttraumatic panophthalmitis & 01 & 00.1 & 00.08 \\
\hline \multicolumn{4}{|l|}{ Chronic } \\
\hline Nonspecific & 56 & 5.81 & 04.49 \\
\hline Granulomatous & 33 & 3.43 & 02.65 \\
\hline Tuberculous & 25 & 2.60 & 02.00 \\
\hline Foreign body granuloma & 04 & 0.42 & 00.32 \\
\hline Giant cell & 03 & 0.31 & 00.24 \\
\hline Xanthogranuloma & 01 & 00.1 & 00.08 \\
\hline
\end{tabular}




\section{Continued}

Cystic

Dermoid cyst

Epidermal cyst

Hydatid cyst

Lipodermoid cyst

Hemorrhagic cyst

Limbal dermoid

Simple cyst

Chocolate cyst

Inflammatory cysts

Hematic cyst

Inclusion cyst

Lacrimal gland lesions

Adenocystic carcinoma

Pleomorphic adenoma

Lymphomas

Tuberculosis

Foreign body

Miscellaneous

Mikulicz syndrome

Acinic cell tumours

Mucoepidermoid carcinoma

Lacrimal gland abscess

Acute inflammation

Lymphoepithelial proliferation

Vascular

Cavernous hemangioma

Capillary hemangioma

Orbital varices

Lymphangioma

Malignant haemiangio pericytoma

Pericytoma

Carotid cavernous fistula

Cavernous sinus fistula

Cavernous sinus thrombosis

Haemangioblastoma

Malignant angioma

A-V malformation

Optic nerve lesions

Optic nerve glioma

Meningioma

Pseudo tumor

Muscular

Rhabdomyosarcoma

Myositis

Nervous tissue related lesions

Neurofibroma

Schwanoma

Hyperthyroidism

Osseous

Osteoma chronic

Osteomyelitis

Chronic osteomyelitis

Soft tissue sarcoma

Congenital lesions

Encephalocoele

Polycystic eye

Heterotropic glial tissue

Histiocytoma

Fatty tissue

\section{6}

76

18

06

06

05

04

03

03

02

02

01

13

53

24

15

05

04

04

02

02

01

01

01

81

48

16

04

04

02

01

01

01

01

01

54

28

26

45

44
10.11

06.09

01.40

00.48

00.48

00.40

00.32

00.24

00.24

00.16

00.08

00.08

09.07

04.25

01.92

01.20

00.40

00.32

00.32

00.16

00.16

00.08

00.08

00.08

00.08

06.50

3.85

1.28

0.32

0.32

0.16

0.08

0.08

0.08

0.08

0.08

0.08

0.08

04.33

02.24

02.09

03.61

03.53

03.13

00.40

02.81

2.01

00.80

00.64

00.64

00.32

00.24

00.08

00.48

00.32

00.16

00.08

00.08

00.08

00.08 




Figure 3. Retinoblastoma with fungating mass.

Table 2. Frequency \& break up of secondary orbital lesions.

\begin{tabular}{|c|c|c|c|}
\hline \multicolumn{4}{|c|}{ SECONDARY ORBITAL LESIONS } \\
\hline LESIONS & Frequency (n) & $\begin{array}{l}\text { Proportion of secondary } \\
\text { orbital lesions (\%) }\end{array}$ & $\begin{array}{c}\text { Proportion of } \\
\text { total lesions (\%) }\end{array}$ \\
\hline Eyelids & 145 & 62.50 & 11.63 \\
\hline Sq cell carcinoma & 89 & 38.36 & 07.14 \\
\hline Haemangioma & 19 & 8.19 & 01.52 \\
\hline Basal cell carcinoma & 17 & 7.33 & 01.36 \\
\hline Sebaceous cell carcinoma & 12 & 5.17 & 00.96 \\
\hline Malignant melanoma & 05 & 2.15 & 00.40 \\
\hline Malignant sebaceous cyst & 02 & 0.86 & 00.16 \\
\hline Adenocarcinoma & 01 & 0.43 & 00.08 \\
\hline Paranasal sinuses & 86 & 37.07 & 06.90 \\
\hline \multicolumn{4}{|l|}{ Ethmoid sinus } \\
\hline Ch ethmoiditis & 43 & 18.53 & 03.45 \\
\hline Orbital fracture & 02 & 0.86 & 00.16 \\
\hline Inverted papilloma & 01 & 0.43 & 00.08 \\
\hline Inflammed nasal polyp & 01 & 0.43 & 00.08 \\
\hline Ethmoidocele & 01 & 0.43 & 00.08 \\
\hline \multicolumn{4}{|l|}{ Frontal sinuses } \\
\hline Frontocele & 01 & 0.43 & 00.08 \\
\hline Mucocele & 08 & 3.45 & 00.64 \\
\hline Pyocele & 08 & 3.45 & 00.64 \\
\hline Dacryocele & 01 & 0.43 & 00.08 \\
\hline \multicolumn{4}{|l|}{ Maxillary antrum } \\
\hline Maxillary antum & 18 & 7.76 & 01.44 \\
\hline Carcinoma & & & \\
\hline Ameloblastoma & 02 & 0.86 & 00.16 \\
\hline Nasopharynx & 01 & 00.43 & 00.08 \\
\hline Nasopharyngeal fibroma & 01 & 00.43 & 00.08 \\
\hline
\end{tabular}

Table 3. Haematopoietic \& reticuloendothelial tissue lesions.

\begin{tabular}{cccc}
\hline & \multicolumn{4}{c}{ HAEMATOPOIETIC RETICULOENDOTHELIAL } \\
\hline LESIONS & Frequency (n) & $\begin{array}{c}\text { Proportion of haematopoietic } \\
\text { \& reticuloendothelial tissue lesions (\%) }\end{array}$ & $\begin{array}{c}\text { Proportion of } \\
\text { total lesions (\%) }\end{array}$ \\
\hline $\begin{array}{c}\text { Lymphoma/leukemia } \\
\text { Angiolymphoid hyperplasia }\end{array}$ & 44 & 93.62 & 03.53 \\
Plasmacytoma & 01 & 02.13 & 00.08 \\
Castleman's disease & 01 & 02.13 & 00.08 \\
\hline
\end{tabular}


Table 4. Metastatic lesions.

\begin{tabular}{cccc}
\hline & \multicolumn{3}{c}{ METASTATIC } \\
\hline LESIONS & Frequency (n) & Proportion of metastatic lesions (\%) & Proportion of total lesions (\%) \\
\hline Ewing sarcoma & 03 & 75.00 & 00.24 \\
Metastatic lesion of unknown origin & 01 & 25.00 & 00.08 \\
\hline
\end{tabular}

(Table 1), followed by inflammatory 173 (17.96\%) (Figure 4 and Figure 5), cystic lesions 126 (13.08\%) (Figure 6 and Figure 7), lacrimal gland 113 (11.73\%) (Figures 8-12), vascular 81 (8.41\%) (Figure 13), optic nerve 54 (5.60\%) (Figure 14), nervous tissue 35 (3.63\%) (Figure 15), muscular 44 (4.57\%) (Figure 16), pseudo tumor $45(4.67 \%)$, hyperthyroidism $08(0.83 \%)$, soft tissue sarcoma $06(0.62 \%)$, osseous $08(00.64 \%)$, congenital lesions $04(0.41 \%)$ (Figure 17), histiocytoma $01(0.10 \%)$ and fatty tissue $01(0.10 \%)$ lesions.

1) Inflammatory lesions: Inflammatory lesions were mainly chronic 122 (70.5\%) (Figure 5) and acute inflammation (29.5\%) (Figure 4). Chronic inflammations were non-specific 56 (32.37\%), fungal granulomas 33 (19.07\%), tuberculosis 25 (14.45\%), foreign body granuloma 04 (2.31\%), giant cell 03 (1.73\%), and xanthogranuloma 01 (00.58\%), whereas acute inflammatory lesions were orbital celluiitis 29 (16.76\%), orbital abscess 07 (04.05\%), sub-periosteal abscess 13 (7.51\%), epidural abscess 01 (00.58\%), post-traumatic panophthalmitis $01(00.58 \%)$.

2) Ocular lesions: Among the ocular lesions 251 (95.07\%) were Retinoblastoma (Figure 2 and Figure 3) and 12 (4.54\%) were malignant melanoma.

3) Cystic lesions: Cystic lesions were mainly dermoid cyst 76 (60.32\%) (Figure 6), epidermal cyst 18 (14.3\%), hydatid cyst 6 (4.76\%), lipodermoid cyst 6 (4.76\%), hemorrhagic cyst 5 (3.97\%), limbal dermoid 4 (3.17\%), simple cyst 3 (2.38\%), inflammatory cysts 2 (1.58\%), hematic cyst $2(1.58 \%)$ and Inclusion cyst 01 (0.79\%).

4) Lacrimal gland lesions: Analysis of Lacrimal gland lesions revealed adenocystic carcinoma 53 (46.90\%) (Figure 11), pleomorphic adenoma 24 (21.24\%) (Figure 8 and Figure 10), lymphomas 15 (13.27\%), tuberculosis 05 (4.42\%), foreign body 04 (3.54\%), miscellaneous 04 (3.54\%), Mikulicz syndrome 02 (1.77\%), acinic cell tumours $02(1.77 \%)$, lacrimal gland abscess $01(0.88 \%)$, acute inflammation $01(0.88 \%)$ (Figure 4$)$, lymphoepithelial $01(0.88 \%)$ and mucoepidermoid carcinoma $01(0.88 \%)$.

5) Vascular lesions: In the category of vascular lesions of the orbit, cavernous hemangioma 48 (59.25\%) were the commonest followed by capillary hemangioma 16 (19.75\%), orbital varices 04 (4.93\%), lymphangioma 04 (4.93\%), malignant haemiangio-pericytoma 02 (2.46\%). pericytoma 01 (1.23\%), carotid cavernous fistula 01 $(1.23 \%)$, cavernous sinus fistula $01(1.23 \%)$, canvernous sinus thrombosis $01(1.23 \%)$, haemangioblastoms 01 (1.23\%), malignant angioma $01(1.23 \%)$ and $\mathrm{A}-\mathrm{V}$ malformation 01 (1.23\%) were the other less common lesions (Figure 13).

6) Optic nerve lesions: Optic nerve lesions were mainly gliomas 28 (51.85\%) and meningiomas 26 (48.15\%) (Figure 14).

7) Nervous tissues lesions: Nervous tissues lesions comprises of neurofibroma 25 (71.42\%) and schwanoma 10 (28.57\%) (Figure 15).

8) Muscular lesions were mainly rhabdomyosarcoma 39 (88.63\%) with 05 (11.36\%) cases of myositis (Figure 16).

9) Pseudotumors: These were seen in 45 (4.67\%) cases of primary orbital lesions.

10) Osseous lesions: Osseous and bony tissue lesions comprise mainly of osteosarcomas 04 (50.0\%), osteoma 03 (37.50) and chronic osteomyelitis 01 (12.50\%) cases.

11) Congenital orbital lesions were encephalocoele 02 (50.00\%), polycystic eye 01 (25.00\%) and heterotropic glial tissue 01 (25.00\%) (Figure 17).

\subsection{Secondary Orbital Lesions}

Amongst the secondary orbital lesions, lesions of the eyelids were the commonest 145 (62.50\%) followed by the lesions of paranasal sinuses 86 (37.07\%) and nasopharynx 01 (00.43\%) (Table 2).

1) Eyelid lesions: Amongst eyelid lesions squamous cell carcinoma was seen in 89 (61.38\%) cases followed by basal cell carcinoma 17 (11.72\%), haemangioma 19 (13.10\%), sebaceous cell carcinoma 12 (8.28\%), ma- 


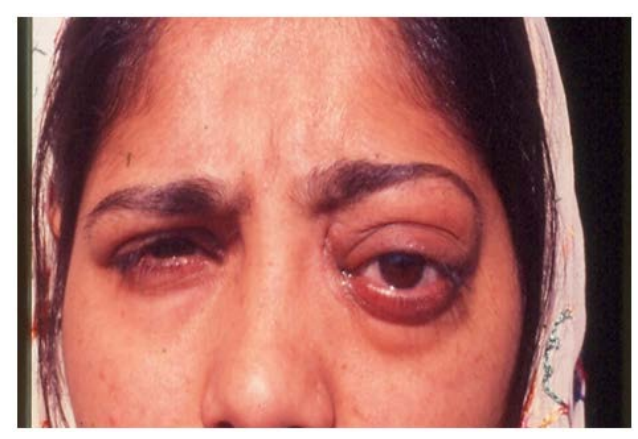

Figure 4. Case of acute inflammation.

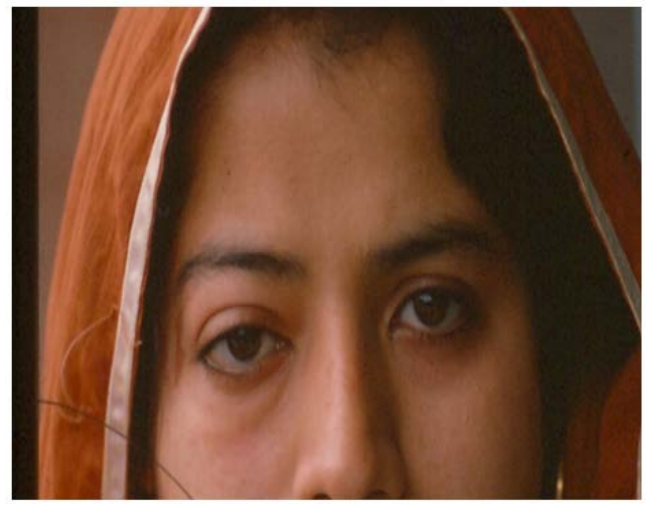

Figure 5. Case of non-specific chronic inflammation.



Figure 6. Case of dermoid cyst.

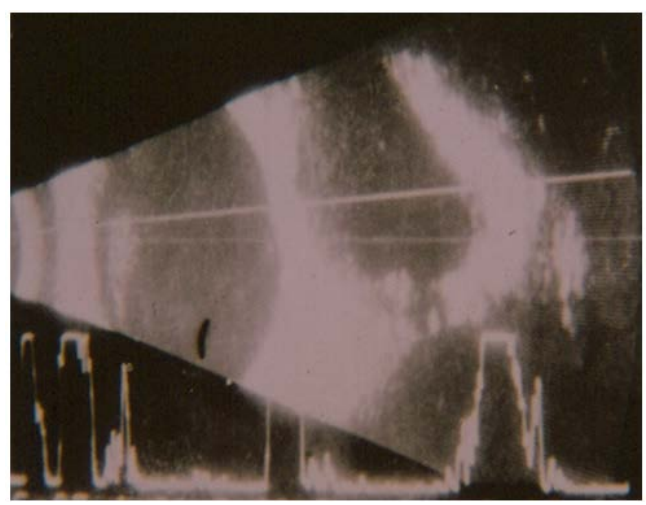

Figure 7. B-Scan showing cystic lesion in superolateral orbit. 




Figure 8. Case of pleomorphic adenoma of lacrimal gland.



Figure 9. CT scan showing mass along whole of roof of orbit.

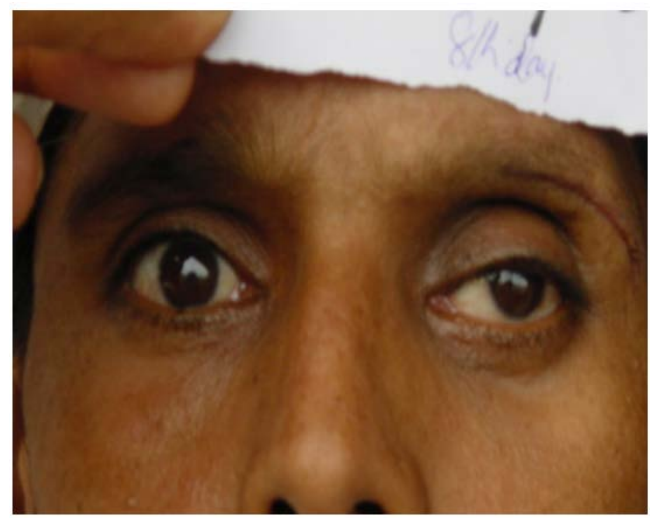

Figure 10. Post operative case of pleomophic adenoma.

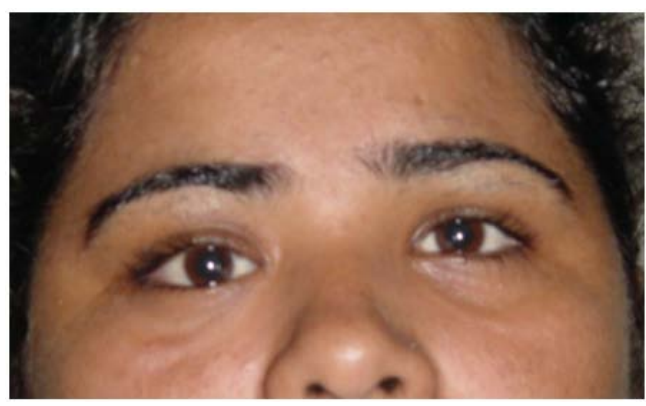

Figure 11. Case of adenocystic carcinoma of lacrimal gland. 


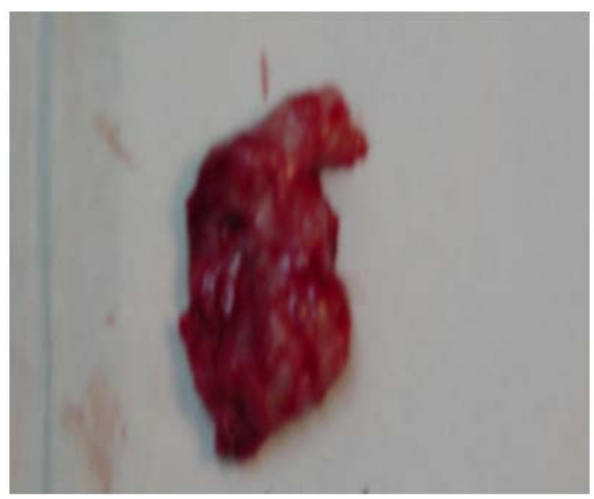

Figure 12. Adenocystic carcinoma of lacrimal gland (tumor removed after lateral orbitotomy).


Figure 13. (a) Preoperative photo of a case of cavernous haemangioma of orbit; (b) B scan; (c) CT scan and (d) Tumour removed after lateral orbitotomy.
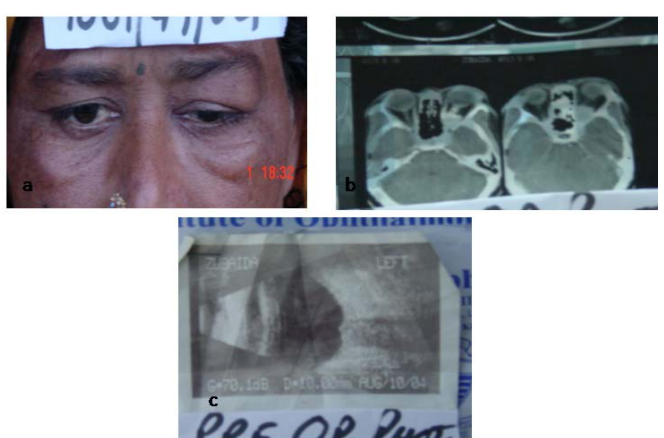

Figure 14. (a) Preoperative picture of meningioma of the optic nerve; (b) CT scan; (c) B scan of the orbit.
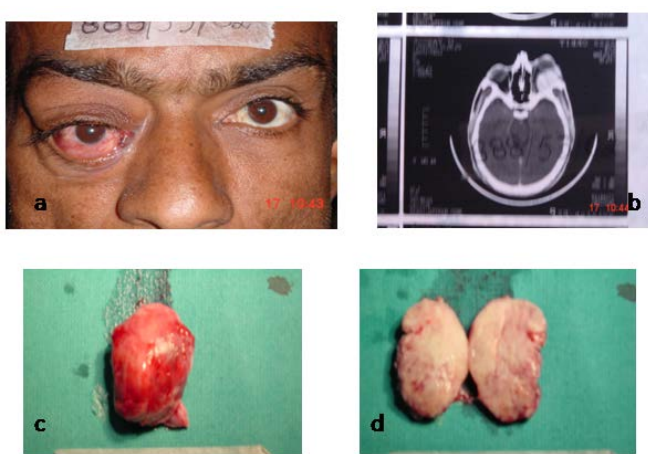

Figure 15. (a) Preoperative picture of a case of schwanoma; (b) CT scan and (c) and (d) Tumour removed after lateral orbitotomy. 


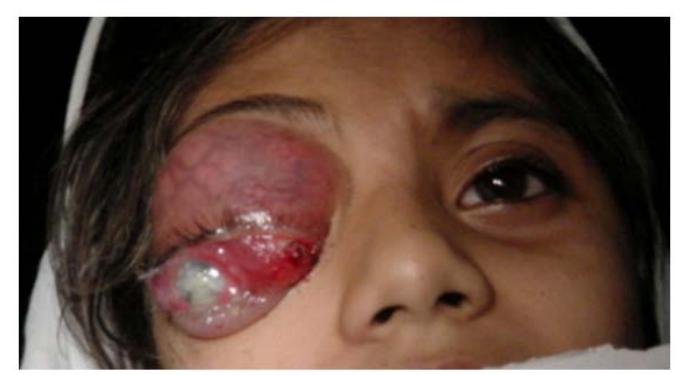

Figure 16. Case of rhabdomyosarcoma.

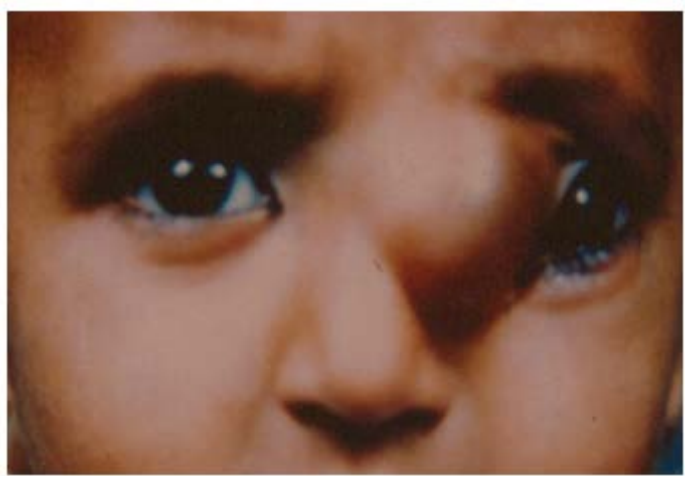

Figure 17. Case of encephalocoele.

lignant melanoma 05 (3.45\%), malignant sebaceous cyst 02 (1.38\%), and adenocarcinoma of meibomian gland 01 (00.69\%) (Figure 18 and Figure 19).

2) Paranasal sinuses: Ethmoidal lesions were the commonest amongst the lesions of paranasal sinuses $48 / 87$ (49.42\%) followed by lesions of the maxillary antrum 20/87 (23\%) and frontal sinus lesions 18/87(20.69\%). chronic ethmoditis was seen in 43 (89.58\%) of cases of ethmoidal lesions, followed by 02 (4.17\%) cases of orbital fracture and 01 (2.08\%) case each of inverted papilloma, inflamed nasal polyp and ethmoidocele. Maxillary antrum carcinoma was seen in $18(90.00 \%)$ case and ameloblastoma in $02(10.00 \%)$ cases with lesions of maxillary antrum. Amongst lesions of frontal sinus 08 (44.44\%) were frontocoele, 08 (44.44\%) mucocele and 02 (11.12\%) of pyocoele (Figure 20 and Figure 21).

3) There was only one case of nasopharyngeal fibroma seen in the series (Figure 22).

\subsection{Haematopoetic \& Reticuloendothelial Lesions}

Amongst the haematopoetic reticuloendothelial lesions, lymphoma/leukemia 44 (93.62\%) were the commonest followed by angiolymphoid hyperplasia 01 (2.13\%), plasmacytoma $01(2.13 \%)$ and castleman's disease 01 (2.13\%) (Figures 23-26; Table 3).

\subsection{Metastatic Lesions}

Amongst the 04 metastatic lesions, 03 (75.0\%) were the Ewing Sarcomas and in 01 (25.0\%) case primary lesion could not be identified (Table 4).

\section{Discussion}

Orbital lesions can be derived from the structures located in the orbit or from the structures surrounding it. Sometimes a distant lesion such as a malignant tumour somewhere else in the body may seed into it. The most common mode of presentation is displacement of the eyeball or proptosis particularly if the lesion is intra-conal. The displacement could be axial (strictly forwards) or non-axial (upwards or downwards in addition to forward displacement). Other presentations could take the form of a palpable tumour which may become a fungating mass if tumour is malignant and sufficient time has elapsed. 




Figure 18. Case of squamous cell carcinoma of eyelid.



Figure 19. Case of malignant melanoma of eye lid.
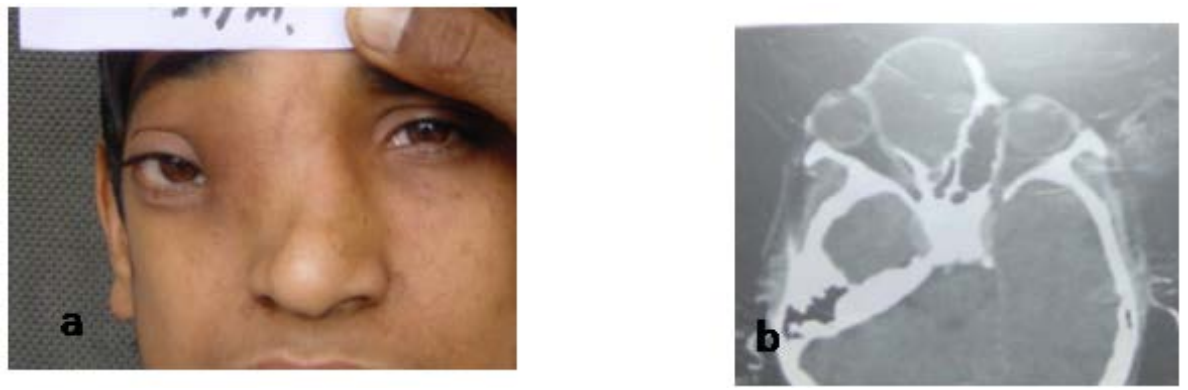

Figure 20. (a) Case of ethmoidocoele; (b) CT scan showing ethmoidocoele.

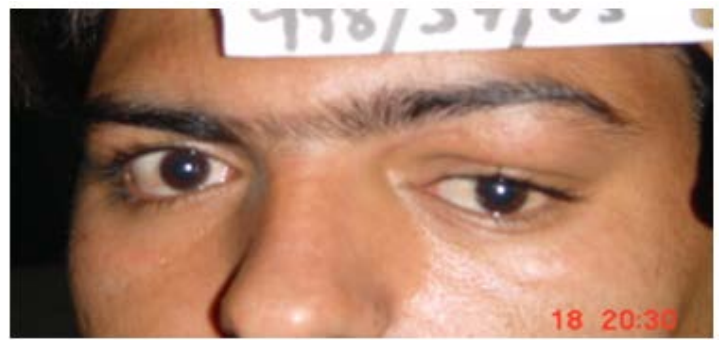

Figure 21. Mucocoele of the frontal sinus causing proptosis. 

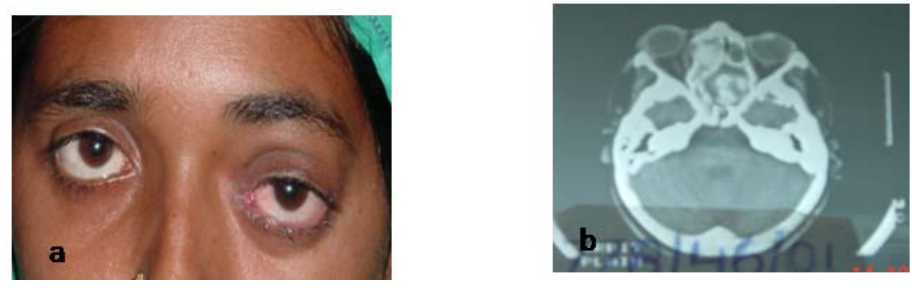

Figure 22. (a) Case of nasopharyngeal fibroma; (b) CT scan showing propotosis.

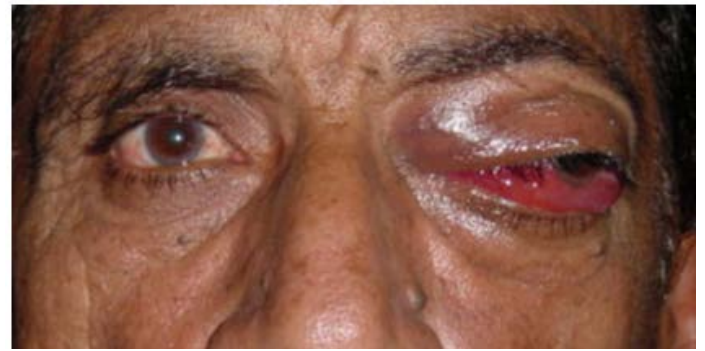

Figure 23. Case of lymphoma of the orbit presenting with proptosis.

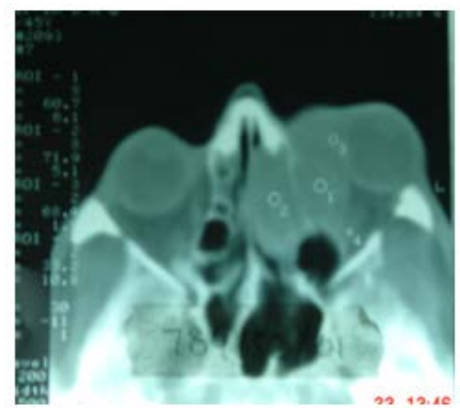

Figure 24. CT scan of the case of lymphoma of the orbit.

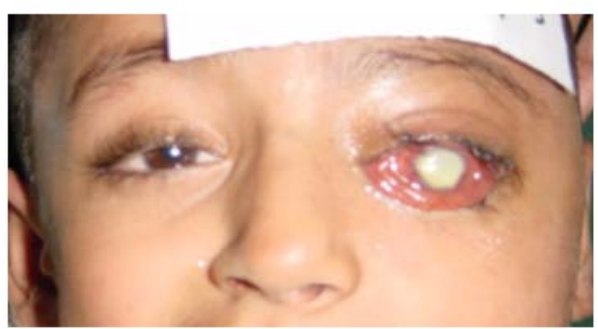

Figure 25. Case of leukemia who presented with proptosis with corneal abscess.

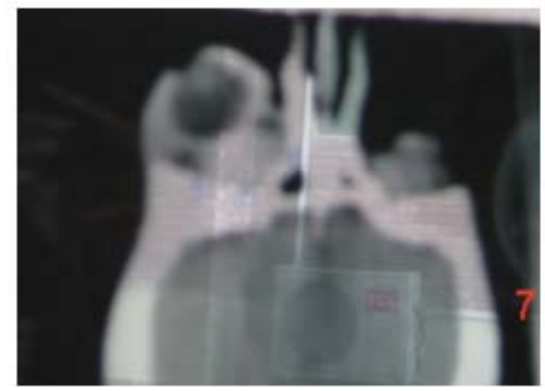

Figure 26. CT scan of the patient with leukemia showing mass in the retrobulbar area. 
The current study has revealed that orbital lesions are more common in adults $57.46 \%(\mathrm{n}=716)$ as compared to children $42.53 \%(n=530)$. Parashkevova found similar distribution according to age in her patients and found that majority (61\%) of patients presented in the sixth and the seventh decade [5].

In our study it was found that neoplastic lesions $54.57 \%(n=680)$ are common than non neoplastic lesions 45.42\% ( $n=566)$ and amongst the neoplastic lesions, malignant lesions $86.17 \%(n=586)$ are more common than benign $13.82 \%(n=94)$. Demirci found similar results where malignant tumors were more common than benign tumors. Out of all cases, 63\% presented with malignancy and 27\% were benign [6]. Similar findings are also reported by Parashkevova who found 56\% cases of malignant tumors and $44 \%$ cases of benign tumors over the period of 4 years [5]. In contrast to this, another study on analysis of space occupying lesions of orbit showed that out of the 2480 lesions, 1697 (68\%) were benign and 783 (32\%) were malignant. The most frequent benign tumors were dermoid cyst (14\%) and cavernous hemangioma (9\%). The most common malignant tumors were non-Hodgkin lymphoma (12\%), basal cell carcinoma (3\%), and orbital metastases (3\%) [7].

Ohtsuka studied orbital tumors in Japanese patients over a period of 20 years and found that out of all patients, 89\% were primary orbital tumors whereas $9 \%$ were secondary tumors originating from neighbouring areas of orbit and $2 \%$ were metastatic tumors [8]. These findings are well aligned with those of our study where Primary orbital lesions originating from the tissues of the orbit, including eyeball, are the most common orbital lesions followed by the secondary orbital lesions, originating from the adjacent structure (eyelids, paranasal sinuses, nasopharynx \& cranial cavity), lesions of the haemopoeitic reticuloendothelial system lesions and metastatic lesions. In 2008, a study conducted by Angotti-Neto reported similar results in 11-year histopathalogical analysis of orbital tumors. He found that out that of the studied 181 orbital space-occupying lesions, 70\% were primary, 23\% secondary, 6\% metastatic and lymphomas, and 1\% was not classified [9].

\section{Conclusions}

Orbital lesions are more common in adults $57.46 \%(n=716)$ as compared to children $42.53 \%(n=530)$. Neoplastic lesions $54.57 \%(n=680)$ are more common than nonneoplastic lesions $45.42 \%(n=566)$, and amongst the neoplastic lesions, malignant lesions $86.17 \%(n=586)$ are more common than benign $13.82 \%(n=94)$. Primary orbital lesions originating from the tissues of the orbita, including eyeball, are the most common orbital lesions followed by the secondary orbital lesions, originating from the adjacent structure (eyelids, paranasal sinuses, nasopharynx \& cranial cavity), lesions of the haemopoitic reticuloendothelial system lesions and metastatic lesions.

Amongst the primary orbital lesions, retinoblastoma, nonspecific inflammations, fungal and tuberculous granulomas, pseudotumours, dermoid cysts, adenocystic carcinoma \& pleomorphic adenoma of lacrimal gland, cavernous haemangioma, optic nerve Glioma and meningioma, neurofibroma, rhabdomyosarcoma are the common orbital lesions. Amongst secondary orbital lesions, squamous cell carcinoma of the eyelid, chronic ethmoiditis and maxillary antrum carcinoma are the common lesions. Lymphomas/leukemias are also seen in good percentage in reticuloendothelial system lesions whereas metastatic lesions are very uncommon.

\section{References}

[1] Lemke, B.N. and Lucarelli, M.J. (2012) Anatomy of the ocular Adnexa, Orbit and Related Facial Structures. In: Black, E.H., Nesi, F.A., Gladstone, G.J. and Levine, M.R., Eds., Smith and Nesi's Ophthalmic Plastic and Reconstructive Surgery, 3rd Edition, Springer Science + Business Media, LLC, New York, 3-58. http://dx.doi.org/10.1007/978-1-4614-0971-7_1

[2] Costin, B.R., Perry, J.D. and Foster, J.A. (2014) Classification of Orbital Tumors. In: Perry, J.D. and Singh, A.D., Eds., Clinical Ophthalmic Oncology, Springer-Verlag, Berlin Heidelberg, 9-14. http://dx.doi.org/10.1007/978-3-642-40492-4 2

[3] Rootman, J. and Nugent, R.A. (2003) Structure of the Orbit: Anatomic and Imaging Features. In: Rootman, J., Ed., Diseases of the Orbit: A Multidisciplinary Approach, 2nd Edition, Lippincott, Williams and Wilkins, Philadelphia, 1-15.

[4] Khan, A.A., Amjad, M., Azher, A.N. and Sarwar, M.S. (1998) Orbital Lesions in Children. Pakistan Journal of Ophthalmology, 14, 86-89.

[5] Parashkevova, B. and Balabanov, C. (2007) Orbital Tumors-Clinical Cases Presentation. Journal of IMAB-Annual Proceeding (Scientific Papers), 13, Book 1.

[6] Demirci, H., Shields, C.L., Shields, J.A., Honavar, S.G., Mercado, G.J. and Tovilla, J.C. (2002) Orbital Tumors in the 
Older Adult Population. Ophthalmology, 109, 243-248. http://dx.doi.org/10.1016/S0161-6420(01)00932-0

[7] Bonavolontà, G., Strianese, D., Grassi, P., Comune, C., Tranfa, F., Uccello, G. and Iuliano, A. (2013) An Analysis of 2,480 Space-Occupying Lesions of the Orbit from 1976 to 2011. Ophthalmic Plastic and Reconstructive Surgery, 29, 79-86. http://dx.doi.org/10.1097/IOP.0b013e31827a7622

[8] Ohtsuka, K., Hashimoto, M. and Suzuki, Y. (2005) A Review of 244 Orbital Tumors in Japanese Patients during a 21-Year Period: Origins and Locations. Japanese Journal of Ophthalmology, 49, 49-55. http://dx.doi.org/10.1007/s10384-004-0147-y

[9] Angotti Neto, H., Cunha, L.P., Gasparin, F., Santo, R.M. and Monteiro, M.L. (2008) Orbital Space-Occupying Lesions: an 11-Year Study of Cases with Histopathologic Analysis Seen at Hospital das Clínicas of FMUSP. Arquivos Brasileiros de Oftalmologia, 71, 809-812. http://dx.doi.org/10.1590/S0004-27492008000600008 